\title{
Effect of Build Orientation on the Corrosion Behavior and Mechanical Properties of Selective Laser Melted Ti-6Al-4V
}

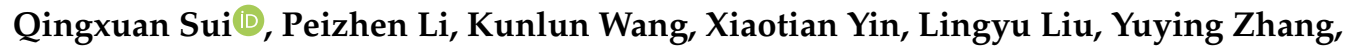 \\ Qingxia Zhang, Shenghai Wang * and Li Wang *
}

School of Mechanical, Electrical \& Information Engineering, Shandong University (Weihai), Weihai 264209, China

* Correspondence: shenghaiw@163.com (S.W.); wanglihxf@sdu.edu.cn (L.W.); Tel.: +86-631-5688224 (S.W. \& L.W.)

Received: 7 August 2019; Accepted: 28 August 2019; Published: 3 September 2019

\begin{abstract}
Ti-6Al-4V alloys with different build orientations have been fabricated by selective laser melting (SLM). The corrosion behavior and mechanical properties have been studied. Investigation of microstructures were characterized by optical microscopy $(\mathrm{OM})$, scanning electron microscopy (SEM), and X-ray diffraction (XRD) analysis. Electrochemical results show that the vertical sample and horizontal sample possess excellent corrosion resistance in the cross section and longitudinal section respectively, which can be attributed to the presence of less acicular $\alpha^{\prime}$ martensite and more $\beta$ phase. Mechanical properties of all samples were determined by compression testing and hardness measurements. The compression strength $\left(\sigma_{c}\right)$ and plastic deformation $\left(\varepsilon_{p}\right)$ of the horizontal sample were higher than those of the vertical sample and the sample with building direction of $45^{\circ}$, because the molten pool boundaries (MPBs) play a significant role in the microscopic slipping at the loading SLM parts. In addition, the sample with building orientation of $45^{\circ}$ achieved highest hardness. Therefore, distinct anisotropy due to different build orientations.
\end{abstract}

Keywords: selective laser melting; Ti-6Al-4V alloy; build orientation; corrosion resistance; mechanical properties

\section{Introduction}

Titanium (Ti) alloys have attractive properties such as higher specific strength to weight ratio, super-plasticity, excellent biocompatibility, and better corrosion resistance. Nowadays, Ti and its alloys are becoming more and more important in the marine, auto, aviation, and space industries [1-5]. Among them, Ti-6Al-4V alloys is the most common Ti alloy. Ti-6Al-4V alloy has an excellent corrosion resistance due to the stable, passive oxide layer formed on its surface, so it is the one most widely used for many engineering components and bio-medical and dental implants due to its superb corrosion resistance [6-12]. Ti-6Al-4V is a duplex structured alloy which contains a hexagonal close packed (hcp) $\alpha$ phase and a body-centered cubic (bcc) $\beta$ phase [13,14]. As is shown in previous studies [15-17], a wide range of microstructures of Ti-6Al-4V can be exhibited through different heat treatment conditions. By Zhao et al. [18] have shown that the original acicular martensite $\alpha^{\prime}$ in the Ti-6Al-4V alloy is converted into a lamellar mixture structure of $\alpha+\beta$ for heat treatment temperatures below the critical temperature $\left(\mathrm{T}_{0} \approx 893^{\circ} \mathrm{C}\right)$, and a basketweave structure was obtained when the heat treatment temperature is above $\mathrm{T}_{0}$. Zhang et al. [19] investigated that the width of primary $\alpha$ laths increases and the aspect ratio and volume fraction of $\alpha$ laths decrease with increasing solution or aging temperature, and the width of primary $\alpha$ laths decrease, the secondary $\alpha$ laths are coarsened and the volume fraction of secondary $\alpha$ 
laths increase with increasing solution and aging time. Depending on heat treatment, the $\alpha / \beta$ volume ratio and chemical composition of the respective constituent phases can be adjusted to yield different properties [20]. The increasing demand for the complexity of parts is mainly due to emerging optimal design methods, such as topology optimization, DFM, and generation design. However, it gives rise to many challenges to some conventional technologies.

SLM is popular as one of important emerging additive manufacturing techniques. Firstly, a thin layer of metal powder is spread on the working platform, and then, the powder is selectively melted by a laser beam depended on a computer model [21]. Schematic diagram of selective laser melting process can be seen in Figure 1. Compared to traditional manufacturing techniques, a wide range of superiority of SLM is revealed, such as a near-net-shape production without the need of expensive molds, a high material utilization rate, and a high level of flexibility. More importantly, the SLM process is be able to produce complex geometrical features owing to the additive and layer-wise production, and cannot be obtained using traditional treatments [22].

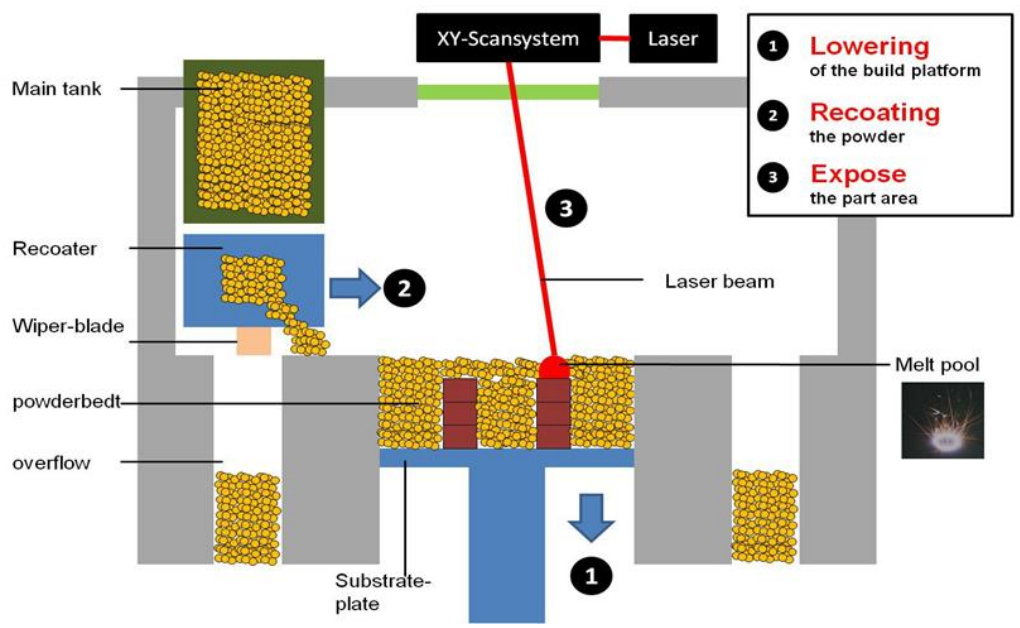

Figure 1. Schematic diagram of selective laser melting process.

Corrosion behavior and mechanical characteristics of the Ti-6Al-4V alloy by SLM-produced in different orientations were studied [23-26]. However, many experiments were focused on corrosion behavior of Ti-6Al-4V alloy in biomedical applications [27-30], its role in marine environments was rarely studied. It is interesting to note that different build orientations in SLM generally result in distinctions in the corrosion resistance and mechanical properties of the SLM-produced Ti-6Al-4V. Therefore, considering that the SLM-produced Ti-6Al-4V alloys are used in the marine environments, it is highly significant to further investigate the corrosion resistance and mechanical characteristics of SLM-produced samples with different build orientations.

\section{Materials and Methods}

\subsection{Sample and Solution Preparations}

Ti-6Al-4V alloy powder prepared by gas atomization was used and the particle size of the powder is in the range of $20-53 \mu \mathrm{m}$, and the particle diameter of $37 \mu \mathrm{m}$ occupies highest proportion. The powder has the high sphericity and a smooth surface is shown in Figure 2. The chemical composition (in wt \%) of Ti-6Al-4V alloy powder is shown in Table 1. SLM parts were manufactured using an SLM 125 HL machine (SLM Solutions, Lubeck, Germany) under a high-purity Ar atmosphere. The machine equipped with a $400 \mathrm{~W}$ Yb: YAG fiber laser with a spot size of $80 \mu \mathrm{m}$. The samples were manufactured with a set of SLM processing parameters: laser power $275 \mathrm{~W}$, scanning speed $1100 \mathrm{~mm} / \mathrm{s}$, scanning spacing $0.12 \mathrm{~mm}$, and powder layer thickness $0.03 \mathrm{~mm}$. In this study, in order to investigate the effect of build orientation on the corrosion resistance and mechanical properties of SLM-produced samples, 
three kinds of specimens were built up in the substrate plane, referred to as sample A (horizontal specimens, and relative density $99.42 \%$ ), sample B (the angle between the specimen direction and substrate plane was $45^{\circ}$, and relative density $99.23 \%$ ) and sample C (vertical specimens, and relative density 99.48\%). The three-dimensional diagram of SLM-produced Ti-6Al-4V alloy is shown in Figure 3, the cube size is $20 \times 10 \times 10 \mathrm{~mm}$ for electrochemical measurements (Figure 3a), and cylindrical specimen size is $3 \mathrm{~mm}$ in diameter and $6 \mathrm{~mm}$ in length for a compression test (Figure 3b). The cross and longitudinal section of every kind samples were prepared for the electrochemical experiments.
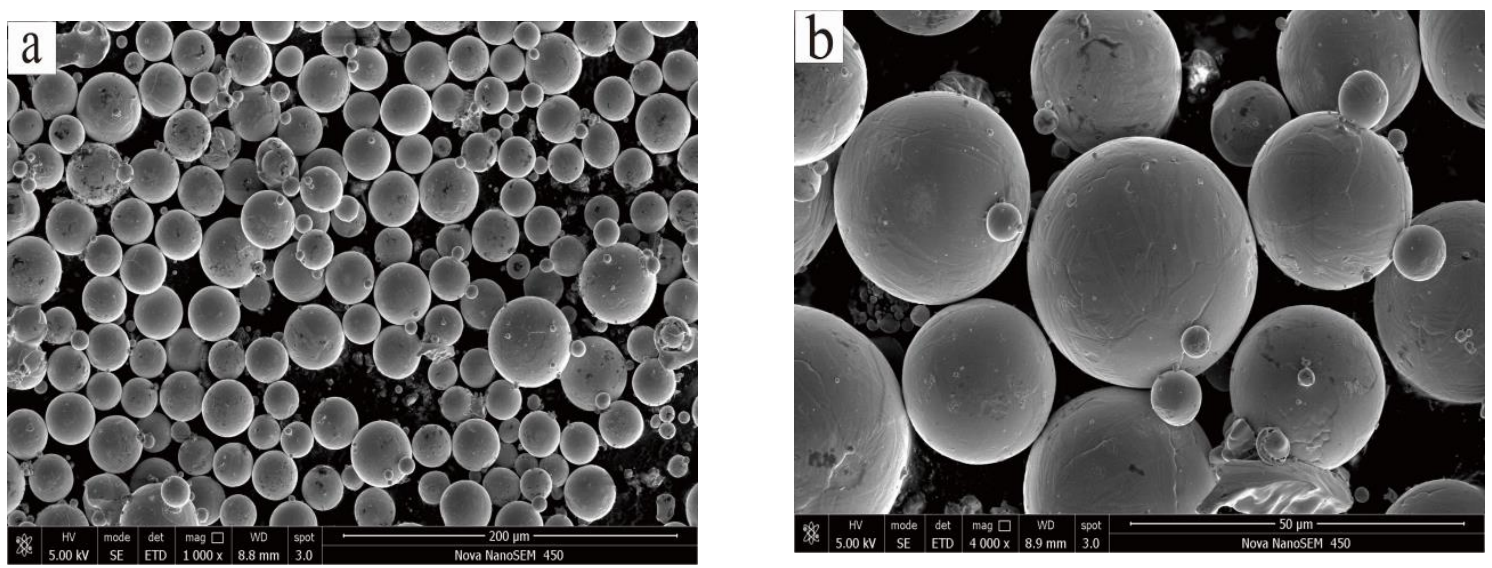

Figure 2. Scanning electron microscopy (SEM) images of the Ti-6Al-4V powders used for low magnification (a) and high magnification (b).

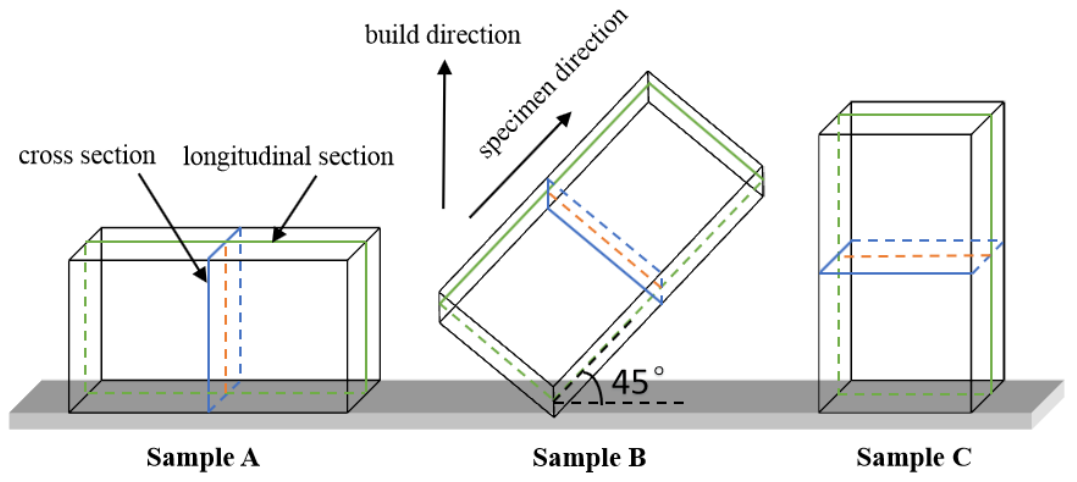

(a)

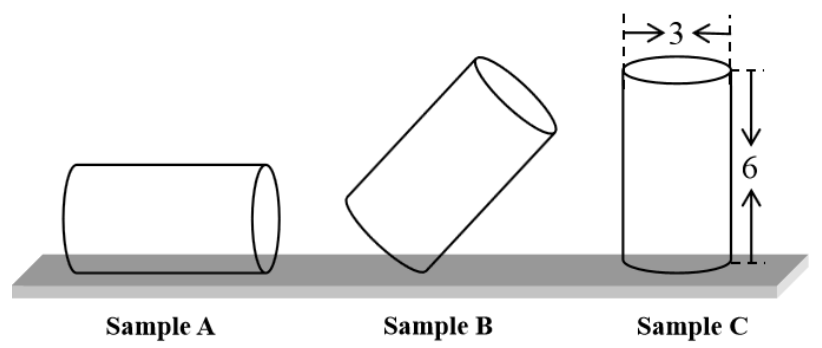

(b)

Figure 3. Strategy of manufacturing of the sample A, B, and C: the cubic specimen for electrochemical measurements (a) and the cylindrical specimen for compression tests (b). 
Table 1. Chemical composition of the Ti-6Al-4V alloy powder.

\begin{tabular}{ccccccccc}
\hline Element & Ti & Al & V & O & N & C & H & Fe \\
\hline Content $($ wt $\%)$ & Balance & $6.0-6.5$ & $3.5-4.5$ & $<0.10$ & $<0.04$ & $<0.08$ & $<0.012$ & $<0.25$ \\
\hline
\end{tabular}

A $3.5 \mathrm{wt} \% \mathrm{NaCl}$ solution was used for the electrochemical measurements. Microstructural examination of the alloy samples was carried out, etched with the Kroll's reagent composed of $3 \mathrm{~mL}$ $\mathrm{HF}, 6 \mathrm{~mL} \mathrm{HNO}_{3}$, and $90 \mathrm{~mL} \mathrm{H}_{2} \mathrm{O}$. Analytical grade reagents and distilled water were prepared in the above-mentioned solutions.

\subsection{Electrochemical Measurements}

Potentiodynamic polarization and electrochemical impedance spectroscopy (EIS) were conducted by CHI660E electrochemical station (CH Instruments Inc., Austin, TX, USA), the Ti-6Al-4V sample as the working electrode, the reference electrode was a saturated calomel electrode (SCE), and the counter electrode was a platinum sheet. Before electrochemical tests, the open circuit potential (OCP) tests were kept enough time to attain a stable OCP in the solution and EIS was acquired at the OCP potentiostatically. The potentiodynamic polarization curves were recorded from potential range of $-1.5 \mathrm{~V}$ to $+1.5 \mathrm{~V}$ versus $\mathrm{OCP}$ at a sweep rate of $3 \mathrm{mV} / \mathrm{s}$. Meanwhile, the electrochemical impedance spectroscopy (EIS) experiments were carried out subsequently at the open-circuit potential in frequency range of $10 \mathrm{mHz}$ to $10 \mathrm{kHz}$ with an $\mathrm{AC}$ amplitude of $5 \mathrm{mV}$. All electrochemical measurements were carried out in $3.5 \mathrm{wt} \% \mathrm{NaCl}$ solution at room temperature and performed at least three times for data reproducibility.

\subsection{Mechanical Properties Test}

Compressive tests were carried with a speed of $0.09 \mathrm{~mm} / \mathrm{s}$ by an UTM5105 electronic universal testing machine (SUNS, Shenzhen, China). All tests were performed at least three times for each condition. Vickers hardness measurements were made using an MHV-100Z micro hardness tester (SCTMC, Shanghai, China) with $100 \mathrm{~g}$ load and $10 \mathrm{~s}$ of dwelling time and an average of 5 indents was taken for each sample.

\subsection{Microstructural Analysis}

The phase analysis of SLM-produced Ti-6Al-4V samples on the cross section and longitudinal section were examined by XRD (Ultima IV, Rigaku, Tokyo, Japan). All XRD patterns were recorded with $2 \theta$ ranging from $20^{\circ}$ to $80^{\circ}$. The contents of the different phases were calculated by using the software Jade 6.0. The microstructural characteristics of samples with different build orientations were examined by OM (CK40M, Olympus Corporation, Tokyo, Japan) and SEM (Nova Nano SEM450, FEI Sirion, Hillsboro, OR, USA).

\section{Results}

\subsection{Microstructural Studies}

Figure 4 shows the XRD patterns for the cross section and longitudinal section of the SLM-produced Ti-6Al-4V alloy samples with different build orientations. Most of the peaks can be indexed as the $\alpha^{\prime}$-Ti phase, and a small amount of phase the body centered cubic (bcc) $\beta$-Ti is also present. Previous studies have shown similar results. In the work of Mierzejewska et al. XRD patterns showed that the $\alpha^{\prime}$ phase was the dominant fraction in as-build samples [31]. In Ref. [26] all peaks of as-built samples were indexed as the $\alpha / \alpha^{\prime}$ phase, while the $\beta$ phase was not detected. The cross section and longitudinal section of the samples consist of the equal phases, while, several value peaks of the main phases display different corresponding intensities. It suggests that different contents of the main phases were formed. As estimated from the fitting XRD results, the ratio of $\alpha^{\prime}$-Ti and $\beta$-Ti phase on 
cross and longitudinal section were estimated shown in Table 2, it is difficult to identify $\alpha$-Ti and $\alpha^{\prime}$-Ti for the two phase, because the two phases have the same hexagonal close-packed (hcp) structure and a similar lattice parameter. Therefore, further confirmation of $\alpha^{\prime}$-Ti phase is made by optical microstructural observations.

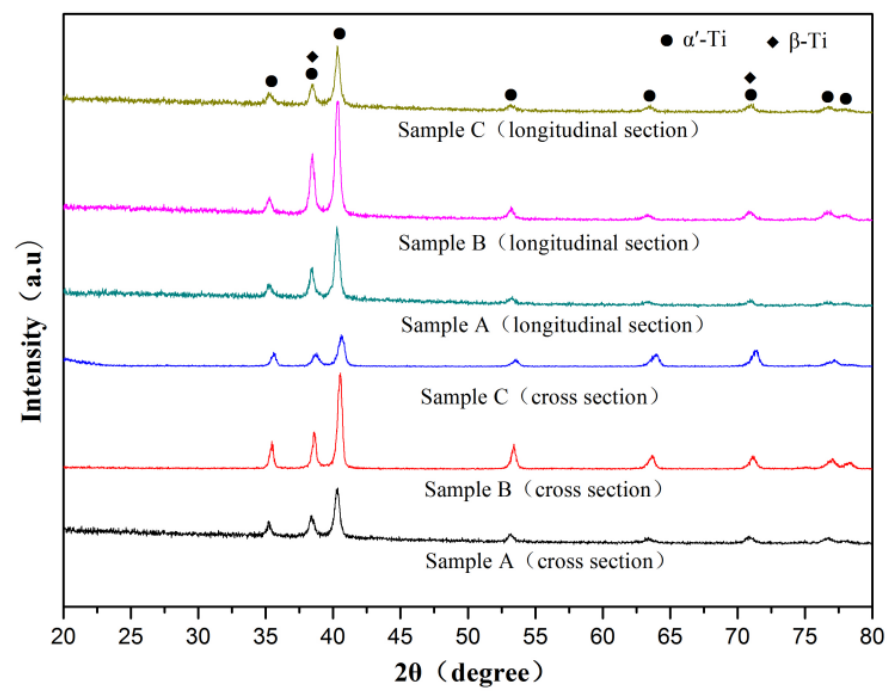

Figure 4. XRD patterns of SLM-produced Ti-6Al-4V samples with different build orientations.

Table 2. Phase constituents and their volume fraction of cross section and longitudinal section of SLM-produced Ti-6Al-4V samples with different build orientations estimated from the XRD patterns.

\begin{tabular}{ccccc}
\hline Section & Sample & Phase Constituents & $\boldsymbol{\alpha}^{\prime}$ & $\boldsymbol{\beta}$ \\
\hline \multirow{3}{*}{ Cross section } & Sample A & $\alpha^{\prime}+\beta$ & 97.9 & 2.1 \\
& Sample B & $\alpha^{\prime}+\beta$ & 96.6 & 3.4 \\
& Sample C & $\alpha^{\prime}+\beta$ & 95.2 & 4.8 \\
\hline \multirow{2}{*}{ Longitudinal } & Sample A & $\alpha^{\prime}+\beta$ & 91.6 & 8.4 \\
section & Sample B & $\alpha^{\prime}+\beta$ & 99.4 & 0.6 \\
& Sample C & $\alpha^{\prime}+\beta$ & 98.6 & 1.4 \\
\hline
\end{tabular}

Figure 5 shows the optical micrographs for the cross section and longitudinal section of the SLM-produced Ti-6Al-4V alloy samples with different build orientations. For the horizontal sample A with cross section (Figure 5a), columnar grains of the prior $\beta$ exhibit epitaxial grow along the build direction, acicular martensite $\alpha^{\prime}$ presents and grows with preferential planes of crystallographic of a $45^{\circ}$ angle to the build direction [32]. The prior $\beta$ is completely transformed to $\alpha^{\prime}$ martensite rather than transforming to $\alpha$, due to the high cooling rate during the SLM process, and a high thermal gradient $\left(10^{4}-10^{5} \mathrm{C} / \mathrm{cm}\right)$ along the build direction in a tiny melt pool $[22,33,34]$. Figure 5 e shows that the prior $\beta$ grains display a square shape in cross section of sample $C$, which can be attributed to scan strategy adopted in the process of SLM (the continuous two layers $15^{\circ}$ in the limitation window). Meanwhile, an overwhelmingly large amount of acicular $\alpha^{\prime}$ martensite is presented upon the prior $\beta$ grains. The microstructure of the longitudinal sections of sample A are presented in Figure $5 b$, it was observed that columnar grains of the primary $\beta$ with $\alpha^{\prime}$ martensite exhibit epitaxial grow along the build direction and parallel to the build orientation, because the columnar grains are oriented along the direction of heat flow. The same situation occurs in the longitudinal section of sample B and sample C, as shown in Figure 5d,f. 

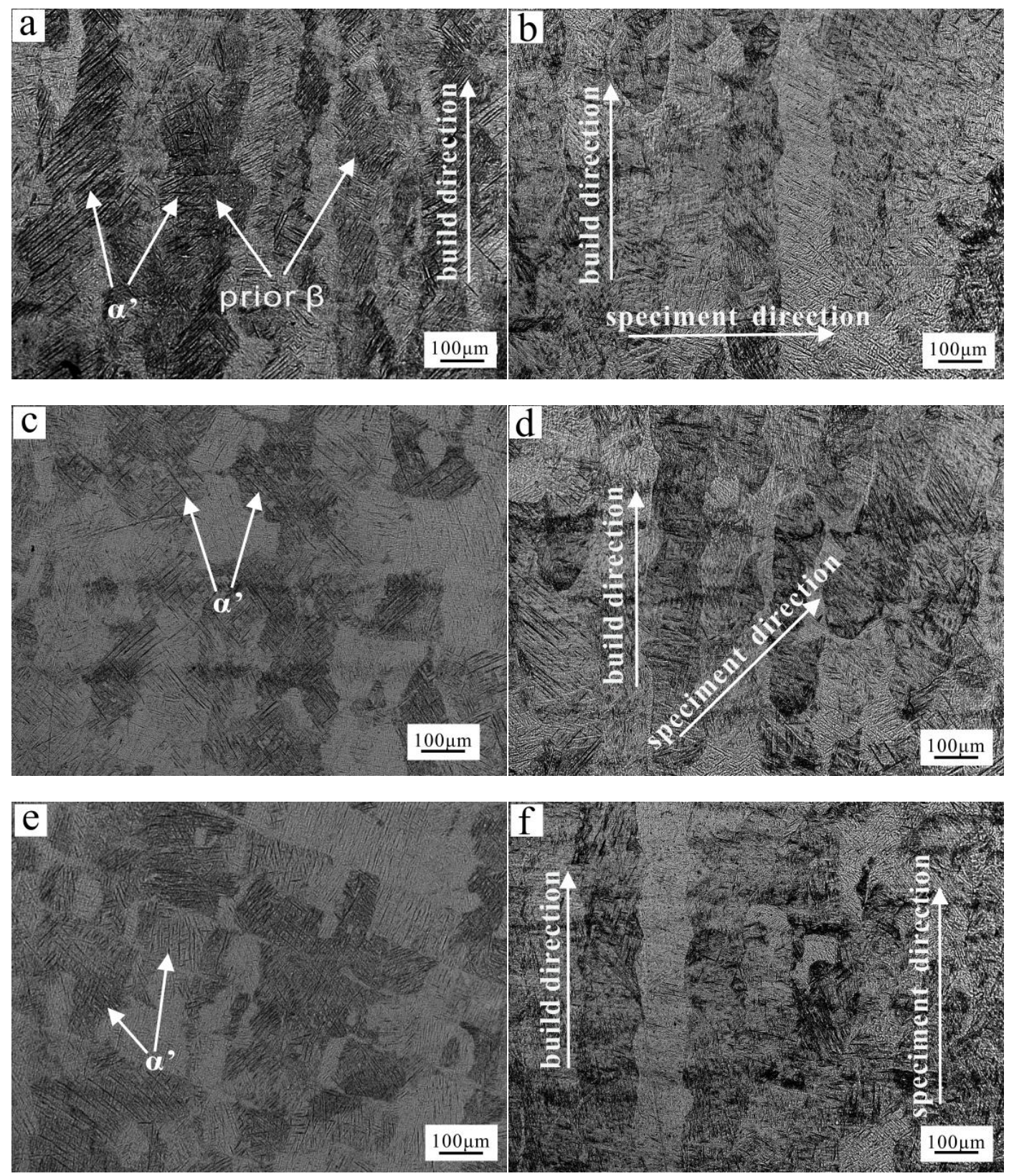

Figure 5. Optical microstructure of SLM-produced Ti-6Al-4V samples with different build orientations. Sample A (cross section (a) and longitudinal section (b)) and sample B (cross section (c) and longitudinal section (d)) and sample $C$ (cross section (e) and longitudinal section (f)).

\subsection{Electrochemical Studies}

Figure 6 shows the potentiodynamic polarization curves of the samples with different build orientations in $3.5 \mathrm{wt} \% \mathrm{NaCl}$ solution, it took enough time to achieve a relatively stable OCP before polarization tests. It is important to judge the ability of corrosion resistance by using some corrosion parameters in the polarization curve, such as the corrosion current density $\left(\mathrm{i}_{\text {corr }}\right)$ and corrosion potential $\left(\mathrm{E}_{\mathrm{corr}}\right)$. The data of corrosion parameters is shown in Table 3. For the corrosion behavior of the cross section of SLM-produced Ti-6Al-4V in $3.5 \mathrm{wt} \% \mathrm{NaCl}$ solution, the $\mathrm{i}_{\text {corr }}$ of the sample $\mathrm{C}$ is the lowest in the group, and the $E_{\text {corr }}$ of the sample $C$ estimated is greater than those of sample $A$ and sample $B$, the above phenomena exhibit that the sample $\mathrm{C}$ has the best corrosion resistance. For the longitudinal section of SLM-produced Ti-6Al-4V, the sample A exhibits a lowest current density. In addition, the 
$\mathrm{E}_{\text {corr }}$ of sample $\mathrm{A}$ is greater than those of other specimens, which indicates the best resistance to corrosion in the group.
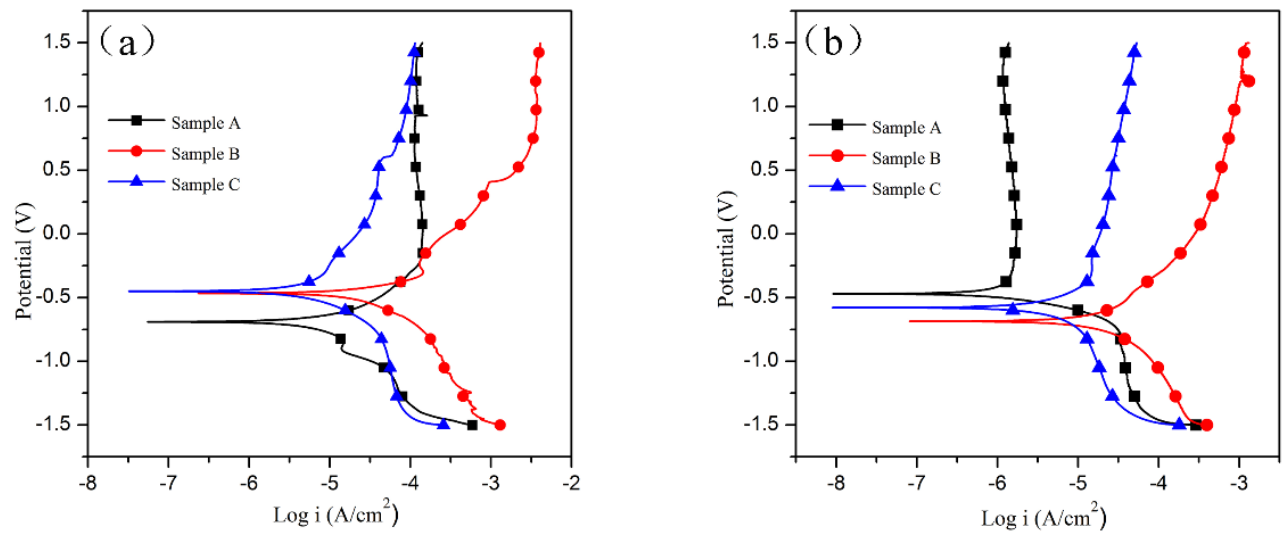

Figure 6. Potentiodynamic curves of SLM-produced Ti-6Al-4V samples with different build orientations: cross section (a) and longitudinal section (b).

Table 3. Electrochemical parameters, $\mathrm{i}_{\mathrm{corr}}$ and $\mathrm{E}_{\mathrm{corr}}$, obtained from the potentiodynamic polarization curves for the cross section and longitudinal section of SLM-produced Ti-6Al-4V samples with different build orientations.

\begin{tabular}{cccc}
\hline Section & Sample & $\mathbf{i}_{\text {corr }}\left(\boldsymbol{\mu A} \cdot \mathbf{c m}^{-2}\right)$ & $\mathbf{E}_{\text {corr }}(\mathbf{V})$ \\
\hline \multirow{3}{*}{ Cross section } & Sample A & 5.929 & -0.690 \\
& Sample B & 19.235 & -0.465 \\
& Sample C & 4.374 & -0.450 \\
\hline \multirow{3}{*}{ Longitudinal section } & Sample A & 1.249 & -0.470 \\
& Sample B & 12.981 & -0.686 \\
& Sample C & 3.392 & -0.578 \\
\hline
\end{tabular}

Figure 7 provides the fitted date via the Nyquist plots and Bode plots for specimens with different build orientations. It is known that if the arc radius of the curve in Nyquist plot is greater, the capability of corrosion resistance is better [35]. Based on the fitted date via the Nyquist plot of sample C with the cross section (Figure 7a), the arc radius of the curve is the largest of all kinds of specimens. This indicates that the charge transfer resistance is the highest in the group and its corrosion resistance is the best. However, the arc radius of the curve of sample B is the smallest, which reveals that the charge transfer resistance is the lowest, and that its corrosion resistance is the worst. According to the longitudinal section of Nyquist plots (Figure $7 \mathrm{~b}$ ), sample A illustrates the largest radius and indicates best corrosion resistance. In addition, the capacitance arc of sample B is smallest, indicating the worst corrosion resistance.

Table 4 summarizes the fitted results of the EIS measurements. In the equivalent circuit, the $R_{\mathrm{S}}$ is the solution resistance and the $R_{c t}$ corresponds to the charge transfer resistance. In general, the $R_{c t}$ is related to the rate of metal dissolving reaction, and it is the resistance of charge transfer through double layer. The $R_{c t}$ value for cross section of sample $C$ is the highest. As for the longitudinal section, the $R_{c t}$ value of sample $A$ is more than ten times greater than the sample $B$ and four times greater than the sample $B$, indicating a best corrosion resistance, the $R_{c t}$ value of sample $B$ is far less than sample $A$ and sample $\mathrm{C}$. The findings mentioned above are in good agreement with the results in polarization tests. 

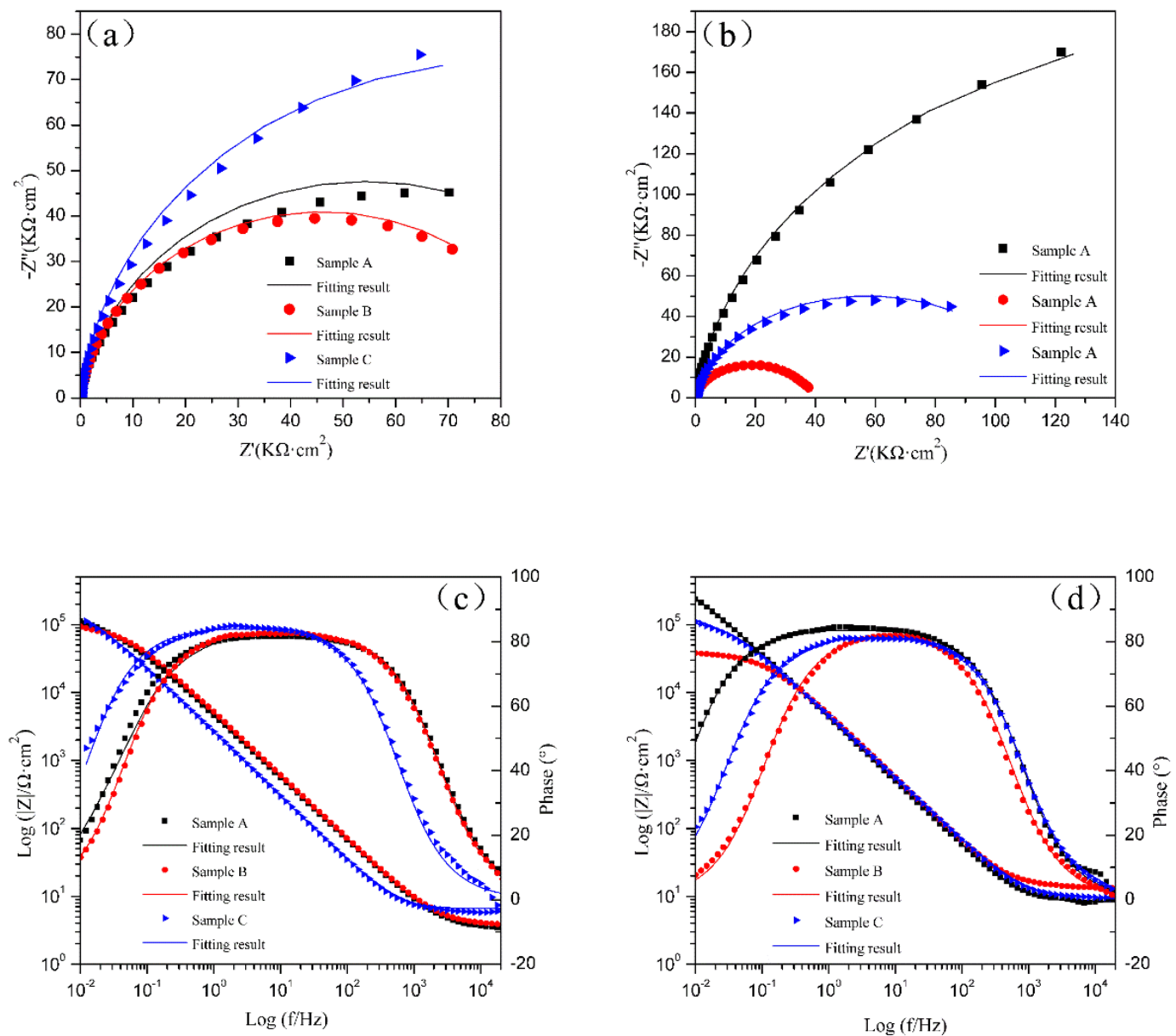

(e)

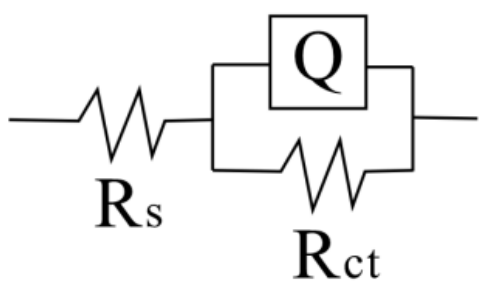

Figure 7. The EIS measurements of SLM-produced Ti-6Al-4V samples with different build orientations: cross section (a) and longitudinal section (b) of Nyquist plots, cross section (c), and longitudinal section (d) of Bode plots and the equivalent circuit model (e).

Table 4. Fitting parameters of EIS measurements for the cross section and longitudinal section of SLM-produced Ti-6Al-4V samples with different build orientations.

\begin{tabular}{cccccc}
\hline Section & Samples & $\mathbf{R}_{\mathbf{c t}}\left(\mathbf{K} \mathbf{\Omega} \cdot \mathbf{c m}^{\mathbf{2}}\right)$ & $\mathbf{R}_{\mathbf{s}} \mathbf{( \Omega \cdot \mathbf { c m } ^ { \mathbf { 2 } } )}$ & $\left.\mathbf{Q} \times \mathbf{1 0}^{-\mathbf{5}}, \mathbf{Y}_{\mathbf{0}} \mathbf{( S \cdot S e c} \mathbf{n} / \mathbf{c m}^{\mathbf{2}}\right)$ & $\mathbf{n}$ \\
\hline \multirow{3}{*}{ Cross section } & Sample A & 108.8 & 3.377 & 4.063 & 0.915 \\
& Sample B & 91.9 & 3.835 & 3.537 & 0.927 \\
& Sample C & 162.5 & 6.560 & 6.844 & 0.941 \\
\hline \multirow{2}{*}{ Longitudinal } & Sample A & 408.4 & 8.315 & 4.238 & 0.934 \\
section & Sample B & 37.2 & 13.55 & 3.862 & 0.927 \\
& Sample C & 114.8 & 9.453 & 4.159 & 0.913 \\
\hline
\end{tabular}




\subsection{Mechanical Properties}

The compression stress-strain curves of samples (A, B, and C) are shown in Figure 8. The $\sigma_{\mathrm{c}}$ and the $\varepsilon_{\mathrm{p}}$ of samples $\mathrm{A}$ are both highest in the group. Vickers hardness measured on the cross and longitudinal section of the all samples is given in Table 5, and the number of samples in each case is three. Regardless of cross section or longitudinal section, sample B showed highest hardness, this is undoubtedly connected with volume fraction of $\mathrm{a}^{\prime}$ phase. An additional factor affecting hardness is lower relative density of SLM produced samples. However, it is different from the research of Weißmann et al., which showed that the hardness of the SLM-manufactured parts manufactured in the $45^{\circ}$ orientation were significantly lower than in those manufactured in the $0^{\circ}$ orientation [23]. These findings indicate the anisotropy in the mechanical properties of SLM parts.

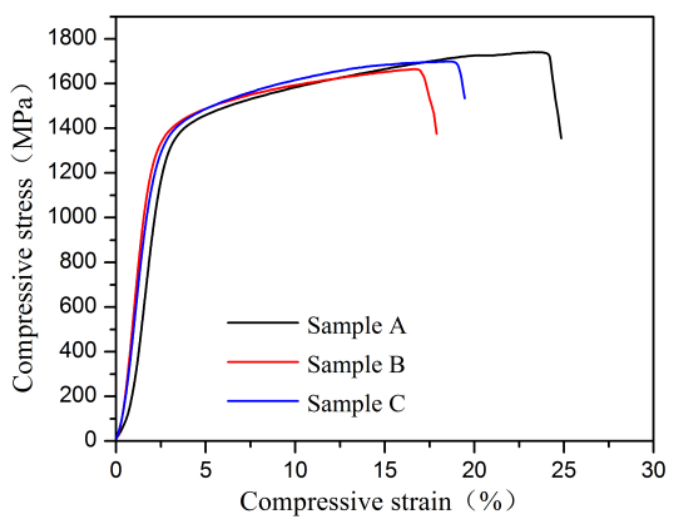

Figure 8. Compressive stress-strain curves of the compression testing for SLM-produced Ti-6Al-4V samples with different build orientations.

Table 5. Results of mechanical tests of SLM-produced Ti-6Al-4V samples with different build orientations.

\begin{tabular}{ccccc}
\hline \multirow{2}{*}{ Samples } & \multirow{2}{*}{$\boldsymbol{\sigma}_{\mathbf{c}}(\mathbf{M P a})$} & \multirow{2}{*}{$\mathcal{\varepsilon}_{\mathbf{p}}(\mathbf{\%})$} & \multicolumn{2}{c}{ Vickers Hardness (HV 0.1/10) } \\
\cline { 3 - 5 } & & & Cross Section & Longitudinal Section \\
\hline Sample A & $1741 \pm 87$ & $23.3 \pm 0.8$ & $381 \pm 6$ & $362 \pm 2$ \\
Sample B & $1665 \pm 41$ & $16.7 \pm 2.4$ & $401 \pm 4$ & $381 \pm 4$ \\
Sample C & $1699 \pm 17$ & $18.6 \pm 4.9$ & $379 \pm 2$ & $374 \pm 3$ \\
\hline
\end{tabular}

\section{Discussion}

In this study, the electrochemical behavior of three kinds of samples with different build orientations have been investigated and compared. Both potentiodynamic and electrochemical impedance spectroscopy (EIS) measurements show that sample $\mathrm{C}$ with cross section and sample A with longitudinal section have the best corrosion resistance. However, no matter for the cross section or longitudinal section, sample B has a worst corrosion resistance.

It is common knowledge that the microstructure of a material has a major impact on its property. Information obtained from the XRD and metallographic analysis reveals that the SLM-produced samples mainly consist of $\alpha^{\prime}$-Ti phase and $\beta$-Ti phase, but with different volume fraction, leading to the difference in corrosion resistance. Estimated from the XRD patterns (Table 2), the amount of $\alpha^{\prime}$-Ti phase in sample $C$ is less than those of sample $A$ and sample $B$ in the cross section. For the longitudinal section of all kinds of samples, the $\alpha^{\prime}$-Ti of sample A has occupied the $91.6 \%$ in the microstructure. Compared with two other samples, the $\alpha^{\prime}$-Ti of sample A is least.

The acicular $\alpha^{\prime}$ martensitic is metastable with regard to corrosion and hold "high energy state", which has the higher dissolution rate of acicular $\alpha^{\prime}$ martensitic than $\beta$-Ti phase [36,37]. In the cross section, the fraction of acicular $\alpha^{\prime}$ martensitic for sample A is greatly high, resulting in an inferior 
corrosion resistance theoretically. However, the presence of the overhanging structure results in the poor density of sample B, the corrosion at the pores will be serious. Sample $C$ exhibits richest corrosion resistance because of less amount of the fraction of $\alpha^{\prime}$-Ti phase. Additionally, the more content of $\beta$-Ti phase also increases the corrosion resistance. The main reason is $\beta$ phase containing more $\mathrm{V}$ content ( $\beta$ stabilisers) [38], the $\beta$ phase possessing more $V$ content plays an important role in improving its resistance to dissolution [20], the high fraction of $\beta$ phase enhances the resistance of charge transfer through the double layer and reduces the rate of metal dissolving reaction [39], the value of $R_{c t}$ can also support the corresponding conclusion.

As known, for the metal ductile deformation of traditional castings and forgings, the main reason is the grain slipping, however, for SLM produced samples besides grain slipping, the MPBs also influence the ductile deformation, which is the main influencing factor. Compared with the grain boundaries, the MPBs have the relative weak bonding ability. According to previous study, there are two types of MPBs, "layer-layer" and "track-track" MPBs in SLM produced samples [40,41]. Figure 9 shows the schematic of the "layer-layer" MPBs and the "track-track" MPBs, the length of "layer-layer" MPBs was longer than that of the "track-track" MPBs. The "layer-layer" MPBs have a parallel relationship, and the grains have the same orientation on two sides of the "layer-layer" MPBs, while the grains on both sides of "track-track" MPBs grow in different orientation. It is difficult for the sample A to slip along the "layer-layer" MPBs surfaces, since the sliding surfaces consisting of "layer-layer" MPBs are always parallel to the compression loading. Consequently, the sliding surfaces consisting of "track-track" MPBs play a role in the ductile deformation for sample A. However, for sample C, the ductile deformation is mainly dependent to the slipping along "layer-layer" MPBs surfaces, and a small part of "track-track" MPBs slips. "layer-layer" MPBs is more difficult to slip compared to "track-track" MPBs, because the grains have the same orientation on two sides of the "layer-layer" MPBs. Theoretically, it has difficultly in slipping for both types of surfaces when SLM part are built completely in the horizontal and vertical direction, whereas the actual MPBs surfaces are not completely regular planes. Therefore, sample A is provided with the excellent ductility. Sample $B$ is involving the combination of the sliding surfaces of the "layer-layer" and "track-track" MPBs in the ductile deformation, which should has the best ductility in theory. However, the minimum value of the $\varepsilon_{\mathrm{p}}$ of sample $B$ is revealed in the experimental results. This changing trend leads to the stress concentration caused by more holes. In addition, the sample B achieves highest hardness, the significant increase in hardness of sample B can be explained by the more formation of $\alpha^{\prime}$ martensitic structure and the poor relative density, since $\alpha^{\prime}$ amartensite shows distortion of crystal lattice, which has a strengthening effect on hardness.

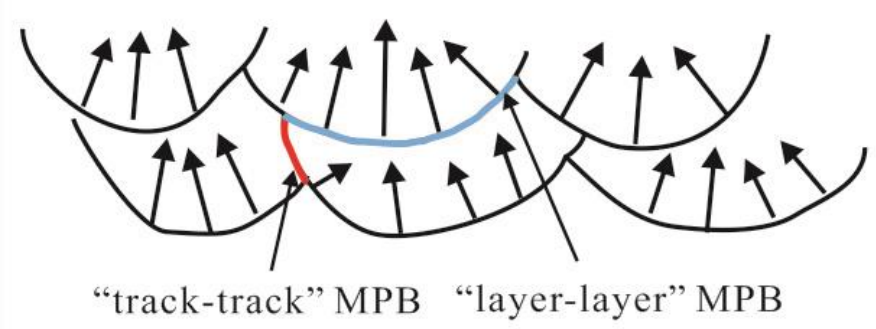

Figure 9. Schematic diagram of the crystallization solidification of molten pools during SLM process.

The different build orientations of the samples caused differences in the surface area of the layers built in the various specimens and then leaded to the difference in temperature field, which is important for the SLM-produced Ti-6Al-4V alloy to select with caution the build orientation for better corrosion resistance and mechanical properties. 


\section{Conclusions}

In this work, the effect of build orientation on the corrosion behavior and mechanical properties of selective laser melted Ti-6Al-4V samples has been studied. For the cross section, the vertical sample shows the best corrosion resistance, while for the longitudinal section, the horizontal sample possess superior corrosion resistance. The difference in the corrosion resistance property can be attributed to the distinction in amount of the $\alpha^{\prime}$-Ti phase and $\beta$-Ti phase in microstructure, less $\alpha^{\prime}$-Ti and more $\beta$-Ti phase make effort to improve the corrosion resistance. The compression strength and ductility of horizontal sample were highest, since "track-track" MPBs play a major role in horizontal sample, "track-track" MPBs were easier to slip than "layer-layer" MPBs. However, stress concentration leads to the inferior compression properties of the sample with build orientation of $45^{\circ}$. In addition, the sample with building orientation of $45^{\circ}$ achieves highest hardness, which can be attributed to the greater formation of $\alpha^{\prime}$ martensitic structure and more holes.

It can be found that different build orientations cause obvious anisotropy from this work. Considering that the SLM-produced Ti-6Al-4V alloys are used in the marine environments, excellent corrosion resistance, and mechanical properties are essential. Thus, the sample with build orientation of $45^{\circ}$ should be avoided, and horizontal or vertical build orientations should be used as far as possible.

Author Contributions: Conceptualization, S.W. and L.W.; Methodology, Q.S., P.L., S.W., and L.W.; Software, P.L., and X.Y.; Validation, Q.S., S.W., and L.W.; Formal analysis, Q.S., X.Y., L.L., Y.Z., and Q.Z.; Investigation, Q.S., and K.W.; Resources, S.W. and L.W.; Data curation, Q.S., L.L., Y.Z., and Q.Z.; Writing一original draft preparation, Q.S.; Writing-review and editing, Q.S., P.L., and K.W.; Visualization, Q.S. and X.Y.; Supervision, S.W. and L.W.; Project administration, S.W. and L.W.; Funding acquisition, S.W. and L.W.; all authors gave the final approval.

Funding: This work was financially supported by the Natural Science Foundation of Shandong Province (no. ZR2019MEM040).

Acknowledgments: The authors are grateful to Qiuhong Huo (Experimentalist), Yanqing Xin (Experimentalist) and Jun Mi (Experimentalist) for technical assistance. The authors are also grateful for the Physical-Chemical Test \& Analysis Center of Shandong University at Weihai.

Conflicts of Interest: The authors declare no conflict of interest.

\section{References}

1. Cho, G.; Kim, K.; Ahn, H.; Cho, K.; Nam, T. Applications of Ti-Ni alloys for secondary batteries. J. Alloys Compd. 2008, 449, 317-321. [CrossRef]

2. Handzlik, P.; Fitzner, K. Corrosion resistance of Ti and Ti-Pd alloy in phosphate buffered saline solutions with and without $\mathrm{H} 2 \mathrm{O} 2$ addition. Trans. Nonferr. Met. Soc. China 2013, 23, 866-875. [CrossRef]

3. Haghighi, S.E.; Lu, H.B.; Jian, G.Y.; Cao, G.H.; Habibi, D.; Zhang, L.C. Effect of $\alpha^{\prime \prime}$ martensite on the microstructure and mechanical properties of beta-type Ti-Fe-Ta alloys. Mater. Des. 2015, 76, 47-54. [CrossRef]

4. He, G.; Eckert, J.; Dai, Q.L.; Sui, M.L.; Löser, W.; Hagiwara, M.; Ma, E. Nanostructured Ti-based multi-component alloys with potential for biomedical applications. Biomaterials 2003, 24, 5115-5120. [CrossRef]

5. Brewer, W.D.; Bird, R.K.; Wallace, T.A. Titanium alloys and processing for high speed aircraft. Mater. Sci. Eng. A 1998, 243, 299-304. [CrossRef]

6. Lee, T.M.; Chang, E.; Yang, C.Y. Attachment and proliferation of neonatal rat calvarial osteoblasts on Ti6Al4V: Effect of surface chemistries of the alloy. Biomaterials 2004, 25, 23-32. [CrossRef]

7. Assis, S.L.D.; Wolynec, S.; Costa, I. Corrosion characterization of titanium alloys by electrochemical techniques. Electrochim. Acta 2006, 51, 1815-1819. [CrossRef]

8. Fossati, A.; Borgioli, F.; Galvanetto, E.; Bacci, T. Corrosion resistance properties of plasma nitrided Ti-6Al-4V alloy in nitric acid solutions. Corros. Sci. 2004, 46, 917-927. [CrossRef]

9. Souto, R. Degradation characteristics of hydroxyapatite coatings on orthopaedic TiAlV in simulated physiological media investigated by electrochemical impedance spectroscopy. Biomaterials 2003, 24, 4213-4221. [CrossRef] 
10. Oliveira, N.T.C.; Guastaldi, A.C. Electrochemical behavior of Ti-Mo alloys applied as biomaterial. Corros. Sci. 2008, 50, 938-945. [CrossRef]

11. Bautista, A.; Moral, C.; Blanco, G.; Velasco, F. Influence of sintering on the corrosion behavior of a Ti-6Al-4V alloy. Mater. Corros. 2005, 56, 98-103. [CrossRef]

12. Narayanan, R.; Seshadri, S.K. Point defect model and corrosion of anodic oxide coatings on Ti-6Al-4V. Corros. Sci. 2008, 50, 1521-1529. [CrossRef]

13. Tamilselvi, S.; Raman, V.; Rajendran, N. Corrosion behaviour of Ti-6Al-7Nb and Ti-6Al-4V ELI alloys in the simulated body fluid solution by electrochemical impedance spectroscopy. Electrochim. Acta 2006, 52, 839-846. [CrossRef]

14. Alves, V.A.; Reis, R.Q.; Santos, I.C.B.; Souza, D.G.; Gonçalves, T.D.F.; Pereira-da-Silva, M.A.; Rossi, A.; da Silva, L.A. In situ impedance spectroscopy study of the electrochemical corrosion of Ti and Ti-6Al-4V in simulated body fluid at $25^{\circ} \mathrm{C}$ and $37^{\circ} \mathrm{C}$. Corros. Sci. 2009, 51, 2473-2482. [CrossRef]

15. Zhang, M.; Yang, Y.; Wang, D.; Xiao, Z.; Song, C.; Weng, C. Effect of heat treatment on the microstructure and mechanical properties of Ti6Al4V gradient structures manufactured by selective laser melting. Mater. Sci. Eng. A 2018, 736, 288-297. [CrossRef]

16. Yan, X.; Yin, S.; Chen, C.; Huang, C.; Bolot, R.; Lupoi, R.; Kuang, M.; Ma, W.; Coddet, C.; Liao, H.; et al. Effect of heat treatment on the phase transformation and mechanical properties of Ti6Al4V fabricated by selective laser melting. J. Alloys Compd. 2018, 764, 1056-1071. [CrossRef]

17. Vrancken, B.; Thijs, L.; Kruth, J.; van Humbeeck, J. Heat treatment of Ti6Al4V produced by Selective Laser Melting: Microstructure and mechanical properties. J. Alloys Compd. 2012, 541, 177-185. [CrossRef]

18. Zhao, Z.; Li, L.; Bai, P.; Jin, Y.; Wu, L.; Li, J.; Guan, R.; Qu, H. The Heat Treatment Influence on the Microstructure and Hardness of TC4 Titanium Alloy Manufactured via Selective Laser Melting. Materials 2018, 11, 1318. [CrossRef] [PubMed]

19. Zhang, S.; Lin, X.; Chen, J.; Huang, W. Heat-treated microstructure and mechanical properties of laser solid forming Ti-6Al-4V alloy. Rare Met. 2009, 28, 537-544. [CrossRef]

20. Chen, J.; Tsai, W. In situ corrosion monitoring of Ti-6Al-4V alloy in $\mathrm{H} 2 \mathrm{SO} 4 / \mathrm{HCl}$ mixed solution using electrochemical AFM. Electrochim. Acta 2011, 56, 1746-1751. [CrossRef]

21. Wysocki, B.; Maj, P.; Krawczyńska, A.; Rożniatowski, K.; Zdunek, J.; Kurzydłowski, K.J.; Święszkowski, W. Microstructure and mechanical properties investigation of CP titanium processed by selective laser melting (SLM). J. Mater. Process. Technol. 2017, 241, 13-23. [CrossRef]

22. Thijs, L.; Verhaeghe, F.; Craeghs, T.; Humbeeck, J.V.; Kruth, J. A study of the microstructural evolution during selective laser melting of Ti-6Al-4V. Acta Mater. 2010, 58, 3303-3312. [CrossRef]

23. Weißmann, V.; Drescher, P.; Bader, R.; Seitz, H.; Hansmann, H.; Laufer, N. Comparison of Single Ti6Al4V Struts Made Using Selective Laser Melting and Electron Beam Melting Subject to Part Orientation. Metals 2017, 7, 91. [CrossRef]

24. Zhao, X.; Li, S.; Zhang, M.; Liu, Y.; Sercombe, T.B.; Wang, S.; Hao, Y.; Yang, R.; Murr, L.E. Comparison of the microstructures and mechanical properties of Ti-6Al-4V fabricated by selective laser melting and electron beam melting. Mater. Des. 2016, 95, 21-31. [CrossRef]

25. Simonelli, M.; Tse, Y.Y.; Tuck, C. Effect of the build orientation on the mechanical properties and fracture modes of SLM Ti-6Al-4V. Mater. Sci. Eng. A 2014, 616, 1-11. [CrossRef]

26. He, J.; Li, D.; Jiang, W.; Ke, L.; Qin, G.; Ye, Y.; Qin, Q.; Qiu, D. The Martensitic Transformation and Mechanical Properties of Ti6Al4V Prepared via Selective Laser Melting. Materials 2019, 12, 321. [CrossRef] [PubMed]

27. Brezinová, J.; Hudák, R.; Guzanová, A.; Draganovská, D.; Ižaríková, G.; Koncz, J. Direct Metal Laser Sintering of Ti6Al4V for Biomedical Applications: Microstructure, Corrosion Properties, and Mechanical Treatment of Implants. Metals 2016, 6, 171. [CrossRef]

28. Ibriş, N.; Mirza Rosca, J.C. EIS study of Ti and its alloys in biological media. J. Electroanal. Chem. 2002, 526, 53-62. [CrossRef]

29. González, J.E.G.; Mirza-Rosca, J.C. Study of the corrosion behavior of titanium and some of its alloys for biomedical and dental implant applications. J. Electroanal. Chem. 1999, 471, 109-115. [CrossRef]

30. Silva, D.; Churiaque, C.; Bastos, I.; Sánchez-Amaya, J. Tribocorrosion Study of Ordinary and Laser-Melted Ti6Al4V Alloy. Metals 2016, 6, 253. [CrossRef]

31. Żaneta Anna, M. Effect of Laser Energy Density, Internal Porosity and Heat Treatment on Mechanical Behavior of Biomedical Ti6A14V Alloy Obtained with DMLS Technology. Materials 2019, 12, 2331. [CrossRef] 
32. Chlebus, E.; Kuźnicka, B.; Kurzynowski, T.; Dybała, B. Microstructure and mechanical behaviour of $\mathrm{Ti}-6 \mathrm{Al}-7 \mathrm{Nb}$ alloy produced by selective laser melting. Mater. Charact. 2011, 62, 488-495. [CrossRef]

33. Rafi, H.K.; Starr, T.L.; Stucker, B.E. A comparison of the tensile, fatigue, and fracture behavior of Ti-6Al-4V and 15-5 PH stainless steel parts made by selective laser melting. Int. J. Adv. Manuf. Technol. 2013, 69, 1299-1309. [CrossRef]

34. Zhang, L.; Attar, H. Selective Laser Melting of Titanium Alloys and Titanium Matrix Composites for Biomedical Applications: A Review. Adv. Eng. Mater. 2016, 18, 463-475. [CrossRef]

35. Chen, L.Y.; Huang, J.C.; Lin, C.H.; Pan, C.T.; Chen, S.Y.; Yang, T.L.; Lin, D.Y.; Lin, H.K.; Jang, J.S.C. Anisotropic response of Ti-6Al-4V alloy fabricated by 3D printing selective laser melting. Mater. Sci. Eng. A 2017, 682, 389-395. [CrossRef]

36. Dai, N.; Zhang, L.; Zhang, J.; Chen, Q.; Wu, M. Corrosion behavior of selective laser melted Ti-6Al-4 V alloy in $\mathrm{NaCl}$ solution. Corros. Sci. 2016, 102, 484-489. [CrossRef]

37. Dai, N.; Zhang, L.; Zhang, J.; Zhang, X.; Ni, Q.; Chen, Y.; Wu, M.; Yang, C. Distinction in corrosion resistance of selective laser melted Ti-6Al-4V alloy on different planes. Corros. Sci. 2016, 111, 703-710. [CrossRef]

38. Safdar, A.; Wei, L.Y.; Snis, A.; Lai, Z. Evaluation of microstructural development in electron beam melted Ti-6Al-4V. Mater. Charact. 2012, 65, 8-15. [CrossRef]

39. Bai, Y.; Gai, X.; Li, S.; Zhang, L.; Liu, Y.; Hao, Y.; Zhang, X.; Yang, R.; Gao, Y. Improved corrosion behaviour of electron beam melted Ti-6Al-4V alloy in phosphate buffered saline. Corros. Sci. 2017, 123, 289-296. [CrossRef]

40. Dai, D.; Gu, D.; Zhang, H.; Xiong, J.; Ma, C.; Hong, C.; Poprawe, R. Influence of scan strategy and molten pool configuration on microstructures and tensile properties of selective laser melting additive manufactured aluminum based parts. Opt. Laser Technol. 2018, 99, 91-100. [CrossRef]

41. Wen, S.; Li, S.; Wei, Q.; Chunze, Y.; Zhang, S.; Shi, Y. Effect of molten pool boundaries on the mechanical properties of selective laser melting parts. J. Mater. Process. Technol. 2014, 214, 2660-2667. [CrossRef]

(C) 2019 by the authors. Licensee MDPI, Basel, Switzerland. This article is an open access article distributed under the terms and conditions of the Creative Commons Attribution (CC BY) license (http://creativecommons.org/licenses/by/4.0/). 